\title{
Filmes Poliméricos Baseados em Amido e Lignossulfonatos: Preparação, Propriedades e Avaliação da Biodegradação
}

\author{
Marina Rodrigues Campagner, Virgínia Aparecida da Silva Moris \\ Departamento de Engenharia de Produção - DEPS, Universidade Federal de São Carlos - UFSCar, \\ Sorocaba, SP, Brasil \\ Leonardo Machado Pitombo, Janaina Braga do Carmo \\ Departamento de Ciências Ambientais, Universidade Federal de São Carlos - UFSCar, \\ Sorocaba, SP, Brasil \\ Jane Maria Faulstich de Paiva \\ Departamento de Engenharia de Produção - DEPS, Universidade Federal de São Carlos - UFSCar, \\ Sorocaba, SP, Brasil
}
Programa de Pós-graduação em Ciência dos Materiais - PPGCM, Universidade Federal de São Carlos - UFSCar, Sorocaba, SP, Brasil

Resumo: Este trabalho envolveu a obtenção de filmes poliméricos a partir de amido de milho e incorporação de lignina na forma de lignossulfonato. A motivação deste trabalho está relacionada à utilização do amido na obtenção de filmes devido ao seu potencial de biodegradação, além do aproveitamento de resíduos de lignossulfonatos provenientes da indústria de celulose e papel. Para a obtenção dos filmes foram utilizados lignossulfonatos em pó e foram realizadas diversas moldagens com variação do tipo e da proporção (1\% a 4\%) de lignossulfonato utilizado. Algumas análises foram realizadas nos filmes poliméricos para comparar propriedades térmicas por DSC (Calorimetria Exploratória Diferencial), e propriedades de tração, em equipamento de DMTA (Análise Térmica Dinâmico-Mecânica). Neste estudo são destacadas as análises da biodegradação e da emissão dos gases liberados utilizando a técnica de Cromatografia Gasosa. De acordo com os resultados de DMTA, a maioria dos filmes poliméricos contendo lignossulfonatos apresentou resistência à tração inferior quando comparados aos filmes poliméricos sem lignossulfonatos (1,024 MPa). Porém, os filmes contendo lignossulfonato modificado com sódio (Vixil S) apresentaram maiores valores de resistência à tração quando comparado aos outros filmes contendo os lignossulfonatos utilizados (Vixil I e Vixil Tan). Nas análises térmicas foram notadas semelhanças entre os dois tipos principais de filmes poliméricos (amido; e amido com lignossulfonato), com alguns deslocamentos das temperaturas dos principais picos máximos dos filmes contendo lignossulfonato (4\%, Vixil S). $\mathrm{Na}$ análise de biodegradabilidade foi verificado que os materiais são biodegradáveis e houve uma emissão maior de $\mathrm{CO}_{2}$ e $\mathrm{N}_{2} \mathrm{O}$ das amostras dos filmes contendo $4 \%$ lignossulfonato do tipo Vixil S, em comparação com as amostras sem lignossulfonato.

Palavras-chave: Filme polimérico, amido, lignossulfonato, DMTA, DSC, biodegradação.

\section{Polymeric Films Based on Starch and lignosulfonates: Preparation, Properties and Evaluation of Biodegradation}

\begin{abstract}
We obtained polymer films from corn starch with lignin incorporation as lignosulfonate. The motivation is the use of starch in obtaining films, due to their potential for biodegradation, and the use of lignosulfonate waste from the pulp and paper industry. To obtain films of lignosulfonates various powders of lignosulfonate were used, varying type and proportion ( $1 \%$ to $4 \%$ ). Analyses were performed on polymer films to compare thermal properties by Differential Scanning Calorimetry, and tensile properties in Dynamic Mechanical Thermal Analysis, DMTA. We emphasize analyses of biodegradation and gas emission using gas chromatography. According to the results of DMTA, most polymeric films containing lignosulfonates showed lower tensile strength when compared to polymer films without lignosulfonates (1.024 MPa). However, the films containing lignosulfonate modified with sodium (Vixil S) showed higher tensile strength when compared to other films containing lignosulfonates (Vixil I and Vixil Tan). With some displacement of the main maximum peak temperatures for the films containing lignosulfonate (4\% Vixil S), thermal analysis similarities between the two main types of polymer films (starch and starch with lignosulfonate) were observed. All materials are biodegradable, but higher $\mathrm{CO}_{2}$ and $\mathrm{N}_{2} \mathrm{O}$ emissions were observed for samples of the films containing $4 \%$ lignosulfonate type, Vixil S, compared to the samples without lignosulfonate.
\end{abstract}

Keywords: Polymeric film, starch, lignosulfonate, DMTA, DSC, biodegradation.

Autor para correspondência: Jane M. F. de Paiva, Programa de Pós-graduação em Ciência dos Materiais - PPGCM, Universidade Federal de São Carlos - UFSCar, Rodovia João Leme dos Santos, Km 110, CEP 18052-780, Sorocaba, SP, Brasil, e-mail: jane@ufscar.br 


\section{Introdução}

Há muitos anos os plásticos derivados de matériasprimas provenientes de petróleo são utilizados em diversas áreas da indústria e comércio devido às suas propriedades, versatilidade e preço, tudo isso atrelado a uma vasta variedade de aplicações ${ }^{[1]}$.

Porém, há alguns anos a preocupação com o meioambiente tem aumentado, já que materiais poliméricos convencionais apresentam degradação natural muito lenta. Além disso, devido sua origem não renovável, há uma série de resíduos gerados pelo descarte dos plásticos sintéticos e, geralmente, a reciclagem consome quantidades significativas de energia térmica ${ }^{[2]}$. Adicionalmente, a poluição do meio ambiente devido ao descarte de polímeros sintéticos sem nenhum controle é uma grande preocupação mundial, visto que alguns podem levar 100 anos ou mais para se decomporem totalmente. Isso pode ser explicado pelo fato desses materiais, geralmente, apresentarem resistência ao ataque de microrganismos, às radiações, ao calor, à água e à oxidação ao $\operatorname{ar}^{[3]}$.

Assim, há alguns anos têm aumentado o interesse na utilização de polímeros biodegradáveis na obtenção de produtos $^{[4]}$ e o amido está revolucionando o mercado de descartáveis ${ }^{[5]}$.

Os amidos são polissacarídeos que podem ser utilizados como matrizes poliméricas termoplásticas. Isto se deve à capacidade do amido de formar um material semelhante ao plástico quando desestruturado na presença de temperatura e, muitas vezes, pressão e cisalhamento. Além disso, várias vantagens atribuídas ao amido levam ao interesse de sua incorporação em misturas poliméricas, como seu baixo custo e o fato de ser abundante e renovável ${ }^{[5,6]}$. Ainda, o amido pode ser processado por técnicas usuais de processamento de polímeros como extrusão, injeção, sopro, termoformagem ${ }^{[7-11]}$.

O grânulo de amido é formado por dois componentes: a amilose e a amilopectina. A amilose é formada por unidades de glicose unidas por ligações glicosídicas $\alpha-1,4$, originando uma cadeia linear. Já a amilopectina é formada por unidades de glicose unidas em $\alpha-1,4$ e $\alpha-1,6$, formando uma estrutura ramificada $^{[9]}$.

Para a obtenção do amido termoplástico é necessário destruir a estrutura semicristalina original dos grânulos ${ }^{[8]}$. Para isto, o grânulo de amido deve ser hidratado na presença de calor para que ocorra primeiramente o entumescimento, até seu consequente rompimento. Nesta etapa, ocorre a completa desestruturação do grânulo devido à alta temperatura e forças de cisalhamento ${ }^{[9]}$. Forma-se, então, o gel de amido que, quando seco, se transforma em uma matriz polimérica flexível[10].

Embora não possuam comportamento totalmente termoplástico, como o apresentado por alguns polímeros tradicionais obtidos a partir de derivados de petróleo, os amidos termoplásticos podem ser transformados pelos mesmos processos. Porém, apresentam algumas limitações, já que as propriedades mecânicas geralmente são inferiores ${ }^{[8,11]}$.
Os filmes poliméricos à base de amido, assim como alguns outros filmes poliméricos, também podem ser obtidos pelo método de moldagem do tipo casting ${ }^{[12]}$. No caso da utilização de solução que contém amido, este método consiste em, primeiramente, gelatinizar o amido para desestruturar os grânulos, seguida de uma etapa de deposição em um molde e posterior secagem em estufa para obtenção do filme polimérico termoplástico.

Os polímeros de amido tendem a apresentar comportamento biodegradável. Outros polímeros que, geralmente, apresentam este tipo de comportamento são os poli-hidroxibutirato (PHB) e derivados. Porém, esses polímeros comerciais apresentam um alto custo de produção (cerca de 5 a 8 vezes mais) em comparação aos polímeros obtidos com reagentes derivados de petróleo ${ }^{[13]}$.

A biodegradação, no caso, consiste na degradação dos materiais poliméricos através da ação de organismos vivos. Desta forma, polímeros biodegradáveis são materiais poliméricos nos quais a degradação resulta primariamente da ação de microorganismos tais como bactérias e fungos. Geralmente, o processo de degradação destes polímeros resulta em gás carbônico $\left(\mathrm{CO}_{2}\right)$, gás metano $\left(\mathrm{CH}_{4}\right)$, outros gases em menores proporções, além de componentes celulares microbianos ${ }^{[14]}$.

A literatura apresenta trabalhos sobre alguns polímeros de potencial biodegradável, como o poli (ácido láctico) (PLA), poli-hidroxialcanoatos (PHA) e polímeros a base de amido que possuem menor impacto ambiental quando comparados a polímeros não biodegradáveis provenientes de fontes fósseis. As principais aplicações dos polímeros biodegradáveis estão relacionadas às embalagens de alimentos (rígidas e flexíveis), sacolas e embalagens de produtos utilizados na agricultura ${ }^{[15-17]}$.

Outro trabalho da literatura apresenta uma pesquisa sobre polímeros a base de amido que envolveu um modelo onde oito variáveis foram consideradas: origem do amido (batata, mandioca, trigo, milho e inhame), concentração de amido e glicerol, teor de amilose, umidade relativa de armazenamento, tempo de envelhecimento dos filmes, tensão de ruptura e resistência à tração na ruptura. Os dados utilizados para validar o modelo foram coletados da literatura (322 trabalhos). Os resultados obtidos com o modelo auxiliam na definição da composição do amido, dependendo de sua origem, relacionando-as com o comportamento mecânico dos filmes ${ }^{[18]}$.

Porém, as propriedades mecânicas de vários polímeros biodegradáveis e a base de amido ainda são muito inferiores às dos polímeros sintéticos ${ }^{[11,15]}$. Por isso, uma alternativa seria a incorporação de cargas ou reforços provenientes, de preferência, de outras substâncias de origem natural para tentar melhorar alguma propriedade mecânica dos polímeros de amido $^{[14-17,19]}$.

Dentro deste contexto, neste trabalho a proposta foi incorporar ao polímero de amido alguns tipos de ligninas extraídas e modificadas na forma de lignossulfonatos, provenientes da indústria de papel e celulose. A lignina é um dos componentes químicos da madeira, nos quais se destacam também a celulose, as polioses (mistura de açúcares), além dos extrativos e cinzas de sais minerais ${ }^{[19]}$. Normalmente, a lignina compreende de $23 \%$ a $33 \%$ em 
madeiras que são comumente usadas nas indústrias de papel, as denominadas madeiras de coníferas, que apresentam a característica de serem macias em comparação com madeiras duras e nobres.

A lignina é uma macromolécula tridimensional amorfa. Por isso, para extraí-la da madeira, principalmente em escala comercial é preciso o uso de vigorosos reagentes químicos, além da utilização da pressão e temperatura. Tais condições de extração da lignina fazem com que essa seja modificada molecularmente, produzindo uma mistura de alta massa molar de compostos fenólicos ${ }^{[19]}$. Devido à característica fenólica, a lignina torna-se interessante para incorporação em resinas poliméricas ${ }^{[20]}$. Os anéis fenólicos presentes na estrutura complexa da lignina permitem também a sua utilização como substituinte parcial do fenol, o qual pode ser empregado em sínteses de alguns tipos polímeros, principalmente, resinas fenólicas, pois a lignina reage com o formaldeído ${ }^{[21-24]}$.

No entanto, apesar da lignina possuir essas vantagens químicas, sua composição exata ainda é de difícil determinação, devido à presença de inúmeras ligações complexas, além de muitos grupos químicos ${ }^{[25]}$. Essa complexidade pode ser explicada também pelo fato da estrutura da lignina conter grupos aromáticos e alifáticos, com inúmeros anéis fenilpropânicos substituídos, ligados através de diferentes tipos de reações ${ }^{[26]}$.

Apesar dessas características químicas, a lignina pode ser reaproveitada para diversos usos ${ }^{[19]}$ como obtenção de lignossulfonatos, e não somente ser queimada em caldeiras industriais para geração de energia, pois é um material com características e propriedades que podem ser aproveitadas para aplicações de maior valor agregado.

Os lignossulfonatos são subprodutos de processos de fabricação da polpa de celulose, denominado também polpação, como os processos sulfito ácido, bissulfito, semi-químico sulfito-neutro ${ }^{[27]}$. Durante a polpação ocorre a liberação da celulose, a lignina é fracionada e solubilizada através da adição covalente de grupos de ácido sulfônico em várias posições na estrutura. Assim, a lignina sulfonada é adicionalmente isolada e depois refinada, obtendo-se o lignossulfonato ${ }^{[28]}$.

O lignossulfonato possui propriedade aglutinante de partículas, ou seja, facilita a junção de partículas ou componentes $^{[29]}$. É interessante citar que existe uma significativa complexidade inerente à estrutura química do lignossulfonato, ou seja, algumas propriedades do lignossulfonato podem mudar de acordo com o tipo de madeira utilizada ${ }^{[30]}$. Os lignossulfonatos que provém de árvores de madeiras duras são diferentes daqueles obtidos de madeiras macias. Tal distinção pode ser explicada devido à diversidade de grupos químicos e à distribuição da massa molar, o que terá efeito nas propriedades dos lignossulfonatos ${ }^{[31]}$. Atrelado à sua natureza anfifílica (na qual parte da molécula é solúvel em água e parte em lipídios), os lignossulfonatos podem também ser utilizados como aditivos em diversas suspensões, com a função de melhorar dispersão e estabilidade ${ }^{[28]}$. Dessa forma, o lignossulfonato pode ser usado em diversas aplicações industriais, tais como: aglomerantes, aditivos para concreto e para cerâmicas, entre outras ${ }^{[31,32]}$.
Neste trabalho aqui apresentado a lignina foi utilizada na forma de lignossulfonato para incorporação em filmes poliméricos de amido. O reaproveitamento de resíduos industriais, como a lignina, e a utilização de amido para formação do filme polimérico colaboram para a redução da quantidade de reagentes ou produtos poliméricos de origem petroquímica, com a vantagem de serem materiais de potencial biodegradável ${ }^{[32]}$. Outro ponto relevante é justamente em relação à biodegradabilidade dos polímeros porque quando são utilizados em algumas áreas há preocupação com a degradação biológica ${ }^{[33]}$.

Na literatura os métodos que usualmente são utilizados para avaliar a biodegradabilidade de polímeros estão relacionados à avaliação da velocidade de crescimento de microorganismos, consumo do substrato (polímero), quantificação do $\mathrm{CO}_{2}$ liberado com utilização do teste de Sturm $^{[34]}$, alterações nas propriedades mecânicas dos polímeros $^{[13,14]}$ e respirometria ${ }^{[35]}$. O método para quantificar a liberação de $\mathrm{CO}_{2}$ geralmente é realizado em solução ou em solo adequado a biodegradação ${ }^{[36]}$.

Neste trabalho aqui apresentado foi realizado um estudo da biodegradabilidade de alguns dos filmes poliméricos obtidos, a fim de analisar as emissões dos gases durante o processo de incubação em latossolo comum em alguns estados do Brasil. Dentre os gases emitidos foram identificados o $\mathrm{CO}_{2}$, que além de ser um gás do efeito estufa, reflete a capacidade do material se decompor, o $\mathrm{N}_{2} \mathrm{O}$ que é emitido em condições especiais a partir de fontes nitrogenadas, e o $\mathrm{CH}_{4}$ que é emitido a partir de fontes orgânicas em condições de anaerobiose.

A análise dos gases foi realizada por cromatografia gasosa, cujos principais objetivos foram a identificação e quantificação rápida de principais gases relacionados ao efeito estufa ${ }^{[37]}$. Ressalta-se que a metodologia de análise da biodegradação e dos gases foi adaptada de outra pesquisa ${ }^{[38]}$. Não foram encontrados na literatura utilização deste método para avaliar biodegradação de filmes poliméricos de amido, ressaltando este trabalho desenvolvido.

Neste trabalho também foi verificada a resistência mecânica à tração dos filmes poliméricos utilizando a técnica de DMTA (Dynamical Mechanical Thermal Analysis). Adicionalmente foram realizadas análises térmicas dos filmes poliméricos por DSC (Differencial Scanning Calorimetry).

\section{Experimental}

Os materiais e equipamentos utilizados para a obtenção dos filmes poliméricos foram: molde no formato de placa circular (diâmetro de $85 \mathrm{~mm}$ ) de material poliacrílico, béqueres; espátulas; balança analítica; aparelho de microondas e estufa com circulação de ar.

Os reagentes utilizados para a moldagem dos filmes poliméricos por casting foram: glicerol purificado (Cromato Produtos Químicos Ltda.), amido de milho em pó com aproximadamente $72 \%$ de amilopectina e $28 \%$ de amilose, água destilada e lignossulfonatos em pó de diferentes tipos: Vixil I (modificado com 1,8\% de cálcio e 1,8\% de magnésio), Vixil S (lignossulfonato modificado com 5,5\% de sódio e 1,6\% de magnésio), e Vixil Tan (lignossulfonato 
modificado com amônio, contendo $1,8 \%$ de N), marca Melbar, fabricados atualmente pela Lignotech Brasil Produtos de Lignina ${ }^{[31]}$.

Inicialmente, para a formação dos filmes poliméricos foram testadas várias porcentagens de glicerol (1, 2,5 e 5\%). Com a utilização das concentrações menores de glicerol (1 e 2,5\%) os filmes poliméricos ficavam rígidos e quebradiços, dificultando a retirada dos mesmos do molde. Por isso, após várias tentativas verificou-se 5\% de glicerol como a melhor composição para se realizar a moldagem por casting, no caso deste trabalho. Assim, para a obtenção dos filmes poliméricos de amido foram utilizados: água destilada (proporção de 90\%), amido de milho (5\%) e glicerol (5\%). Tais componentes foram adequadamente pesados em balança analítica, colocados em um béquer de 1 L e misturados. Em seguida, a mistura foi levada à um aparelho de microondas para o aquecimento, a uma potência de $50 \mathrm{~W}$. No total, a mistura permaneceu aproximadamente 6 minutos no microondas, com algumas pausas para ser homogeneizada e agitada.

Assim que era atingida a termoplasticização do amido e a mistura apresentava a aparência de um gel com certo grau de transparência, a mesma era colocada no molde de poliacrílico e deixada em uma estufa com aquecimento e circulação de ar a $35^{\circ} \mathrm{C}$, por 8 horas. Procedimentos similares foram realizados para a incorporação dos lignossulfonatos na mistura. As porcentagens de lignossulfonatos adicionadas podem ser verificadas na Tabela 1, bem como a quantidade adicionada em cada tipo de filme.

É importante ressaltar que foram moldados filmes poliméricos com lignossulfonato em porcentagens de $1 \%$, $2 \%$ e $4 \%$ para cada um dos tipos de lignossulfonatos (Vixil I, Vixil S e Vixil Tan) utilizados. No total foram obtidos nove diferentes filmes poliméricos contendo lignossulfonatos.

\section{Análise Dinâmico-Mecânica (DMTA)}

Para a realização dos testes no equipamento de DMTA foram cortadas 6 amostras de cada tipo de filme polimérico moldado. Todas as amostras cortadas em formato de tiras, com dimensões aproximadas de $50 \mathrm{~mm}$ de comprimento e $5 \mathrm{~mm}$ de largura, foram submetidas a testes no DMTA, com garra adequada, no modo de tração, com uma pré-carga de $0,5 \mathrm{~N}$, razão de ensaio de $0,8 \mathrm{~N} / \mathrm{min}$, em condição isotérmica a temperatura de aproximadamente $25^{\circ} \mathrm{C}$.

As análises foram realizadas no equipamento DMA, modelo Q800 (marca TA Instruments), alocado no Laboratório de Pesquisa em Materiais (UFSCar/Campus Sorocaba).

Após as análises, o teste de hipóteses de Dixon foi aplicado nos resultados encontrados, a fim de verificar se os valores das extremidades dos testes deveriam ser rejeitados ou não. $\mathrm{O}$ teste de Dixon consiste em um teste bilateral, por isso, são testados os valores mínimo e máximo ${ }^{[39]}$. Para um conjunto de resultados $\mathrm{Z}(\mathrm{h}), \mathrm{h}=1,2, \ldots . \mathrm{H}$, agrupados em ordem crescente, no caso deste trabalho entre 3 e 7, o teste de Dixon utiliza o seguinte critério, citado na Equação 1.

$$
D_{\text {calc }}=\frac{Z(2)-Z(1)}{Z(H)-Z(1)} e \frac{Z(H)-Z(H-1)}{Z(H)-Z(1)}
$$

Com isso, se $\mathrm{D}_{\text {calc }}<\mathrm{D}_{\text {tab5\% }}$, o valor não é rejeitado, ou seja, é considerado aceito.

Se $\mathrm{D}_{\text {tab } 1 \%}>\mathrm{D}_{\text {calc }}>$ Dtab $5 \%$, o valor é considerado suspeito ou estranho.

Se Dcalc $>$ Dtab 1\%, o valor é considerado disperso.

\section{Calorimetria Exploratória Diferencial (DSC)}

Após a moldagem de todos os filmes poliméricos, cada amostra foi submetida à análise de DSC (Differential Scanning Calorimetry) para ser caracterizada termicamente. Tal análise foi realizada no intervalo de temperatura de 0 a $300{ }^{\circ} \mathrm{C}$. A razão de aquecimento utilizada foi de $10{ }^{\circ} \mathrm{C} / \mathrm{min}$ em atmosfera de nitrogênio gasoso, com fluxo de $30 \mathrm{~mL} / \mathrm{min}$.

As análises foram realizadas no equipamento DSC, modelo Q20 (marca TA Instruments), alocado no Laboratório de Pesquisa em Materiais (UFSCar/Campus Sorocaba).

\section{Teste de biodegradabilidade}

Para a realização do teste de biodegradabilidade, as amostras dos filmes foram enterradas em solos incubados em frascos de vidro de $600 \mathrm{~mL}$, realizando medições dos gases emitidos em cada frasco seguindo a metodologia proposta por Carmo et al. ${ }^{[40]} \mathrm{O}$ solo utilizado nas incubações foi classificado como Latossolo Vermelho Eutroférrico ${ }^{[41]}$. Este tipo de solo está presente em extensas áreas nas regiões Centro-Oeste, Sul e Sudeste do Brasil. Na literatura ${ }^{[42]}$ também podem ser encontradas características relacionadas à fertilidade e granulometria deste tipo de solo.

Para o teste de biodegradabilidade foram coletadas amostras dos gases através de seringas de plástico de $20 \mathrm{~mL}$ BD (Becton, Dickinson and Co.). Durante cada evento de amostragem, ou seja, em cada dia de coleta, quatro amostras foram coletadas de cada frasco. A primeira amostra foi coletada no $1^{\mathrm{o}}$. minuto e as amostras subsequentes, após 30, 60 e 90 minutos. Portanto, em cada dia de coleta foram retiradas 4 amostras de cada um dos 9 frascos, resultando em 36 amostras. Considerando todo o experimento foram coletadas 144 amostras.

Tabela 1. Composição de amostras dos filmes poliméricos de amido com incorporação de lignossulfonato.

\begin{tabular}{ccccc}
\hline Tipo de Filme & $\begin{array}{c}\text { Concentração de } \\
\text { lignossulfonato }\end{array}$ & Amido (\%) & Glicerol (\%) \\
\hline L0 & $0 \%$ & 5 & 5 & 5 \\
L1 & $1 \%$ & 5 & 5 & 50 \\
L2 & $2 \%$ & 5 & 59 & 58 \\
L4 & $4 \%$ & 5 & 86 \\
\hline
\end{tabular}


Todas as amostras foram analisadas na Universidade Federal de São Carlos/Campus Sorocaba, utilizando um cromatógrafo a gás, marca Shimadzu, modelo GC-2014. O cromatógrafo foi equipado com uma coluna de enchimento, um detector para analisar o $\mathrm{N}_{2} \mathrm{O}$, e um detector de ionização de chama para quantificar o $\mathrm{CO}_{2}$ e o $\mathrm{CH}_{4}$. O método utilizado é descrito na literatura ${ }^{[43,44]}$.

Para calcular as taxas de emissão, os volumes molares dos gases foram corrigidos para a temperatura ambiente e pressão atmosférica medida no tempo de amostragem. Os fluxos de gases GHG (gases de efeito estufa) foram calculados de acordo com a literatura ${ }^{[45,46]}$, e de acordo com a Equação 2.

$$
\mathrm{f}=\frac{\Delta \mathrm{C}}{\Delta \mathrm{t}} \mathrm{x} \frac{\mathrm{V}}{\mathrm{A}} \mathrm{x} \frac{\mathrm{m}}{\mathrm{V}_{\mathrm{m}}}
$$

Onde, $\Delta \mathrm{C} / \mathrm{Dt}$ é a alteração na concentração de GHG dentro dos frascos durante o período de (Dt) que os frascos são fechados; V e A são, respectivamente, o volume da câmara (frasco) e a área de cobertura do solo pela câmara, $\mathrm{m}$ é a massa molar de cada gás $\left(\mathrm{CO}_{2}, \mathrm{CH}_{4}\right.$ e $\left.\mathrm{N}_{2} \mathrm{O}\right)$. A taxa de emissão para cada experiência foi calculada utilizando uma regressão linear com base na curva gerada a partir dos valores medidos do gás ao longo de intervalos de 30 minutos.

Após todos os cálculos, a próxima etapa consistiu na seleção das amostras para os testes de biodegradabilidade. Como cada teste deveria ser realizado em triplicata de amostras, as amostras selecionadas (conforme explicado a seguir) foram as de filmes com $4 \%$ de lignossulfonato Vixil S, além das amostras $0 \%$ de lignossulfonato, e de gases coletados das amostras controle, ou seja, retiradas dos frascos contendo somente o solo, sem qualquer amostra de filme polimérico.

Em relação aos filmes contendo lignossulfonato, as amostras com 4\% de lignossulfonato Vixil S foram selecionadas para a realização do teste de biodegradabilidade por conterem maior porcentagem de lignossulfonato (considerando as amostras de filmes de Vixil S) e que apresentaram resultados adequados nas análises de DMTA. As amostras foram cortadas em quadrados de $5 \mathrm{~cm} \times 5 \mathrm{~cm}$ (Figura 1), e colocadas dentro de redes de embalagem de alimentos, confeccionadas em polietileno (Figura 2) para que, após os testes, as amostras pudessem ser retiradas mais facilmente de dentro do sistema (frasco de vidro) contendo o solo utilizado.

Desta forma, foram montados nove frascos de vidro contendo sistemas com válvulas adequadas para a completa vedação. Três frascos continham apenas o solo (para controle do sistema), três continham as amostras dos filmes poliméricos de amido ( $0 \%$ de lignossulfonato), e outros três continham as amostras de filmes com $4 \%$ de lignossulfonato Vixil S.

\section{Resultados e Discussão}

Os filmes poliméricos de amido sem lignossulfonato apresentaram características de materiais translúcidos. Durante a obtenção dos filmes poliméricos com lignossulfonatos foi observado que conforme foi adicionado o lignossulfonato, os filmes se tornavam escuros e opacos, revelando uma boa dissolução do lignossulfonato na matriz polimérica de amido. Também foi observado que ocorria alteração de coloração conforme o tipo de lignossulfonato (Vixil I, Vixil S e Vixil Tan) adicionado, devido às diferenças de composições, além das diferenças de porcentagens de lignossulfonatos, ou seja, quanto maior a porcentagem de lignossulfonato utilizada, mais escuros e opacos se tornavam os filmes obtidos.

De cada tipo de filme obtido foram cortadas seis amostras que, posteriormente, foram submetidas aos ensaios de tração em equipamento de DMTA. Os resultados de todas as análises realizadas estão descritos nas Tabelas 2 e 3, e

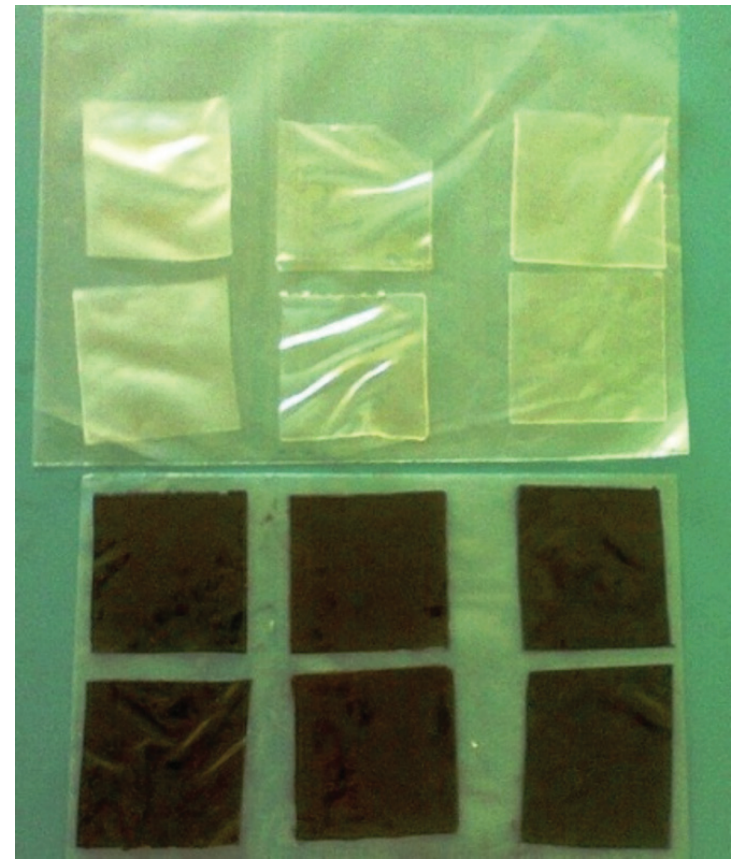

Figura 1. Amostras dos filmes de amido (incolores) e dos filmes com $4 \%$ de lignossulfonato Vixil S (cor escura) cortados nas dimensões $5 \mathrm{~cm} \times 5 \mathrm{~cm}$.

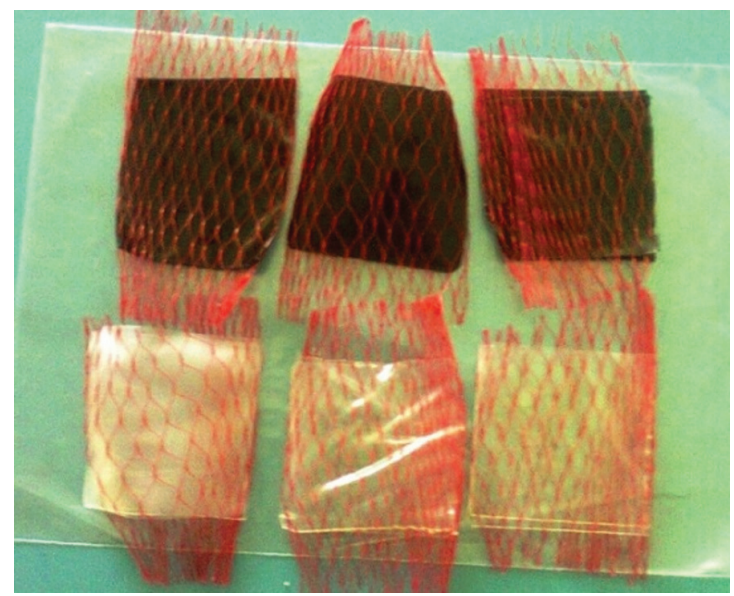

Figura 2. Amostras dos filmes de amido (incolores) e dos filmes com $4 \%$ de lignossulfonato Vixil S (cor escura) colocadas dentro de redes de polietileno. 
foram submetidas ao teste de Dixon. Os valores máximos e mínimos de resistência a tração são, respectivamente, os maiores e menores valores obtidos nos ensaios de tração considerando 6 amostras ensaiadas de cada filme. Algumas das análises realizadas nos filmes com 4\% de lignossulfonato Vixil S podem ser observadas na Figura 3.

De acordo com as curvas (Figura 3) pode ser observado que o filme contendo $4 \%$ de lignossulfonato Vixil S apresentou resultados distintos de deformação. Esta variação nos resultados pode ter acontecido devido a aglomeração de algumas partículas nos filmes e pequenas alterações na espessura das amostras em determinados locais, pois a espessura dos filmes não ficava uniforme durante a moldagem por casting.

Os valores máximos e mínimos de cada um dos resultados das análises no equipamento de DMTA foram submetidos ao teste de Dixon, conforme Equação 1 citada anteriormente, e todos os resultados foram considerados aceitos. Portanto, os valores de Dcalc de todas as amostras foram menores que $\mathrm{D}$ tab $5 \%$, ou seja, $\mathrm{D}_{\text {calc }}<\mathrm{D}_{\text {tab5 } 5 \%}$. Todos os valores mínimos e máximos do teste de Dixon de cada tipo de amostra podem ser verificados na Tabela 2 .
Na Tabela 3 estão apresentadas as médias de resistência à tração e desvio-padrão de seis amostras de cada tipo de filme testado. Comparando os resultados da média de resistência à tração das amostras de filmes contendo Vixil I (Tabela 3 ) com a amostra de $0 \%$ de lignossulfonato pode ser observado que as amostras com lignossulfonato Vixil I foram menos resistentes mecanicamente à medida que a porcentagem do lignossulfonato (Vixil I) era aumentada. Comportamento similar ocorreu com as amostras dos filmes contendo lignossulfonato Vixil Tan, sendo que estas se mostraram menos resistentes à tração, apresentando os menores valores de resistência em relação a todos os tipos de filmes testados.

As amostras de filmes contendo lignossulfonato Vixil $\mathrm{S}$ apresentaram os melhores resultados de resistência à tração entre os filmes contendo lignossulfonatos. As amostras contendo $1 \%$ do lignossulfonato Vixil S inclusive apresentaram valores (Tabelas 2 e 3 ) que ultrapassaram valores de resistência à tração encontrados para a amostra de $0 \%$ de lignossulfonato.

Considerando o desvio-padrão dos filmes contendo lignossulfonatos (Tabela 3), vários tipos de amostras

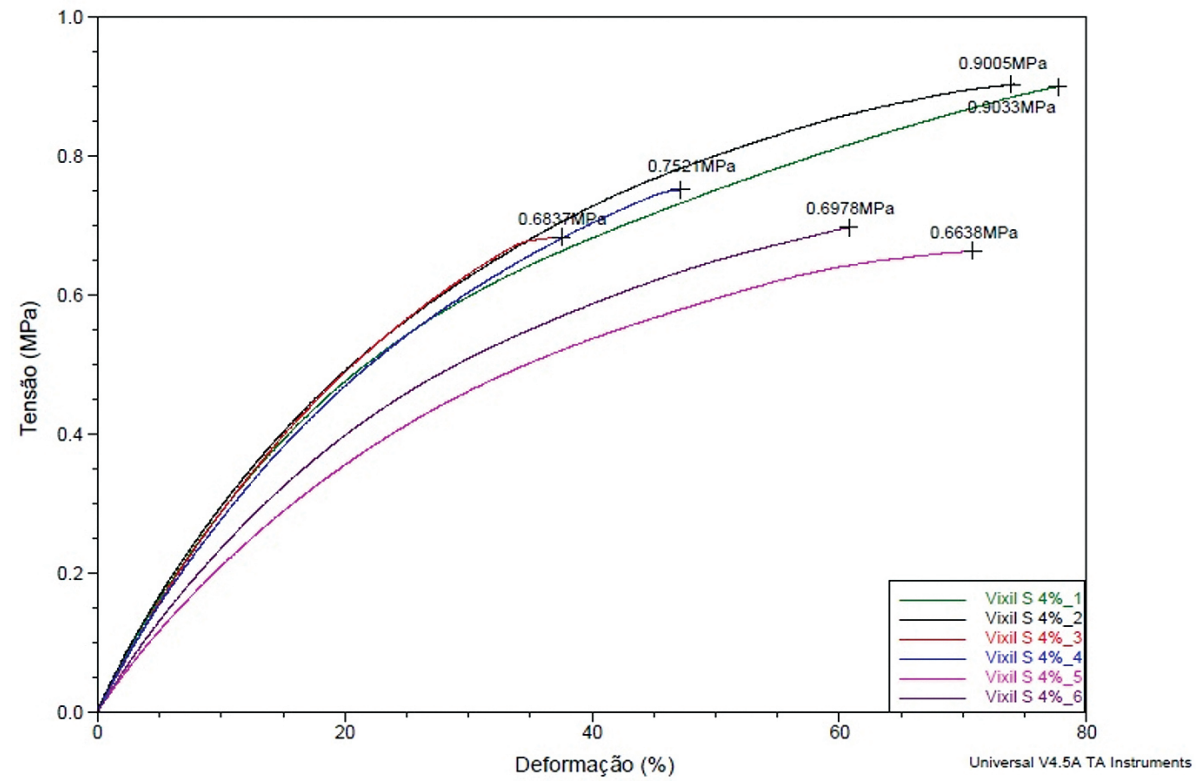

Figura 3. Ensaios no DMTA dos filmes com $4 \%$ de lignossulfonato Vixil S.

Tabela 2. Valores Mínimo e Máximo de Resistência à tração das amostras de filmes testadas no DMTA e Resultados do Teste de Dixon.

\begin{tabular}{ccccc}
\hline $\begin{array}{c}\text { Amostras ensaiadas no } \\
\text { DMTA }\end{array}$ & Mínimo Valor (MPa) & Máximo Valor (MPa) & $\begin{array}{c}\text { Resultados do Teste de } \\
\text { Dixon } \mathbf{D}_{\text {calc (minimo e máximo) }}\end{array}$ & $\begin{array}{c}\text { Resultados do Teste de } \\
\text { Dixon D tab 5\% }\end{array}$ \\
\hline \%\% lignossulfonato & 0,6377 & 1,059 & 0,1844 e 0,212 & 0,569 \\
1\% Vixil I & 0,6714 & 1,059 & 0,349 e 0,018 & 0,628 \\
2\% Vixil I & 0,3258 & 0,7257 & 0,351 e 0,416 & 0,628 \\
4\% Vixil I & 0,2678 & 0,5811 & 0,235 e 0,313 & 0,628 \\
1\% Vixil S & 0,7717 & 1,4130 & 0,451 e 0,022 & 0,628 \\
2\% Vixil S & 0,4687 & 0,6424 & 0,206 e 0,618 & 0,628 \\
$4 \%$ Vixil S & 0,6638 & 0,9033 & 0,083 e 0,011 & 0,628 \\
$1 \%$ Vixil Tan & 0,2320 & 0,9266 & 0,103 e 0,001 & 0,628 \\
$2 \%$ Vixil Tan & 0,2160 & 0,6305 & 0,167 e 0,213 & 0,628 \\
$4 \%$ Vixil Tan & 0,2171 & 0,3417 & 0,154 e 0,130 & 0,628 \\
\hline
\end{tabular}


Tabela 3. Média e desvio padrão de Resistência à Tração dos filmes no ensaio de DMTA.

\begin{tabular}{ccc}
\hline Amostras & Média (MPa) & Desvio padrão \\
\hline $0 \%$ lignossulfonato & 1,0240 & 0,2920 \\
1\% Vixil I & 0,9242 & 0,1555 \\
$2 \%$ Vixil I & 0,5032 & 0,1323 \\
4\% Vixil I & 0,4077 & 0,1127 \\
1\% Vixil S & 1,1480 & 0,2380 \\
$2 \%$ Vixil S & 0,5351 & 0,0651 \\
$4 \%$ Vixil S & 0,7669 & 0,1086 \\
$1 \%$ Vixil Tan & 0,4952 & 0,3012 \\
$2 \%$ Vixil Tan & 0,3851 & 0,1630 \\
$4 \%$ Vixil Tan & 0,2789 & 0,0519 \\
\hline
\end{tabular}

apresentaram menores valores de desvio-padrão, quando comparadas às amostras de filmes poliméricos contendo somente amido de milho.

Em relação às amostras dos filmes contendo $4 \%$ de lignossulfonato, o melhor desempenho das amostras que contém o lignossulfonato Vixil S pode ser explicado pela presença dos íons sódio em sua estrutura, diferentemente dos lignossulfonatos Vixil I e Vixil Tan. Dentre os lignossulfonatos utillizados neste trabalho, o Vixil S é o lignossulfonato que apresenta maior porcentagem de íons presentes, no caso, aproximadamente $5,5 \%$ de sódio e $1,6 \%$ de magnésio. Portanto, o Vixil S é denominado lignossulfonato de sódio, que contém características dispersantes, desenvolvido para melhorar as propriedades tensoativas em relação ao Vixil ${ }^{[31]}$. A ausência de íons de cálcio evita precipitados indesejáveis, os quais geralmente ocorrem com a utilização do Vixil I. Além disto, o lignossulfonato Vixil S apresenta cerca de 13 a 19\% de açúcares redutores em sua composição, que auxilia no poder adesivo, ainda sendo facilmente solúvel em água, sem ocasionar problemas de viscosidade. Assim, a utilização do lignossulfonato de sódio (Vixil S) apresentou propriedades que auxiliaram na formação dos filmes poliméricos, bem como na maior resistência à tração dos filmes contendo Vixil S a 4\% em comparação aos filmes contendo outros tipos de lignossulfonatos a $4 \%$.

$\mathrm{Na}$ literatura é encontrado que alguns tipos de surfactantes podem ocasionar acréscimos ou decréscimos nas propriedades mecânicas de filmes contendo amido ${ }^{[16,47]}$. Ainda, a interação do amido com emulsificantes pode também atrasar substancialmente a propriedade de gelatinização $^{[47]}$.

Um trabalho da literatura ${ }^{[16]}$ relata o efeito da incorporação de alguns tipos de surfactantes nas propriedades físicas de filmes de amido. Para isto foram utilizados diversos surfactantes, como monopalmitato de sorbitano (denominado comercialmente S40), monoestearato de sorbitano (S60) e monooelato de sorbitano (S80) a 15\% em massa, além da utilização de glicerol ( $25 \%$ em massa) e amido de milho. No caso, os autores obtiveram bons resultados de resistência à tração (média de 24,3 $\mathrm{MPa}$ ) do filme de controle (F-C) que não continha surfactante, porém quando foram utilizados os surfactantes também foram observados decréscimos nas propriedades mecânicas de tração, chegando ao valor de $8,4 \mathrm{MPa}$ de resistência à tração quando foi utilizado o surfactante S60. No caso, o decréscimo foi atribuído à formação de uma estrutura mais anisotrópica com a utilização de alguns surfactantes e que ocasionaram redução das forças de coesão.

Em outro trabalho da literatura ${ }^{[48]}$ os autores estudaram o preparo e caracterização de filmes de amido de milho com um tipo de lignossulfonato (em concentrações de 1 a 4\% em massa) modificado com cálcio, juntamente com um modificador do tipo terpolímero de etileno, acrilato de butila $(6 \%)$ e anidrido maleico (3\%), que exerceram a função de agente de reforço aos filmes de amido. As concentrações de glicerol e água utilizadas foram de $35 \%$ e $15 \%$ em massa, respectivamente. Os filmes foram preparados com lignossulfonato em forma de pasta com o objetivo de evitar agregação secundária das partículas. Os resultados relacionados às propriedades mecânicas dos filmes de amido de milho e contendo 1,2 e $4 \%$ de lignossulfonato foram comparados. No caso foi observado que o filme de amido contendo $1 \%$ em massa de lignossulfonato apresentou $3,4 \mathrm{MPa}$ de resistência à tração. Porém, os filmes contendo concentrações maiores de lignossulfonato, ou seja, 2 e $4 \%$ em massa, apresentaram decréscimos nos valores da resistência à tração para $1,7 \mathrm{MPa}$ e 1,4 MPa, respectivamente; além de decréscimos no módulo de Young $(\mathrm{MPa})$ e na porcentagem de alongamento na ruptura ${ }^{[48]}$.

No caso deste trabalho, mesmo os maiores valores de resistência à tração da Tabela 3 , ou seja, das amostras de filmes $0 \%$ de lignossulfonato e das amostras de filmes de Vixil S, quando comparados a alguns trabalhos da literatura $^{[16,48,49]}$ observa-se que os resultados encontrados foram inferiores. Este fato, provavelmente, está relacionado à baixa concentração do plastificante glicerol (5\%) utilizado neste trabalho, em comparação com trabalhos da literatura nos quais foram utilizados $25 \%$ e $35 \%$ em massa de glicerol $^{[16,48]}$, além de outros componentes ou modificadores em alguns casos ${ }^{[49]}$. Ainda, neste trabalho foi utilizado o método de preparação por casting e em alguns trabalhos foram utilizados métodos de moldagem diferentes como, por exemplo, compressão a quente ${ }^{[49]}$.

$\mathrm{Na}$ literatura pode ser encontrado um trabalho ${ }^{[8]}$ que envolveu a utilização de reômetro de torque para a mistura de $70 \%$ de amido e $30 \%$ de glicerol em massa, com posterior moldagem por compressão. Os filmes obtidos apresentaram valor médio de resistência à tração de 2,1 MPa. Porém, quando alguns filmes foram ensaiados em tração, após o condicionamento prévio por 2 semanas em ambiente com $53 \pm 2 \%$ de umidade relativa, em temperatura de $25^{\circ} \mathrm{C}$, o valor médio de resistência à tração foi de $1,7 \mathrm{MPa}^{[8]}$.

Nas Figuras 4 e 5 estão apresentadas algumas curvas das análises de DSC. A Figura 4 apresenta a curva de DSC do filme de amido plastificado na qual pode ser observado um pico endotérmico em aproximadamente $108^{\circ} \mathrm{C}$ relacionado ao processo de fusão da parte cristalina da matriz polimérica do amido e ao processo de evaporação da água residual, a qual atua como plastificante do material. Neste trabalho, durante a preparação do filme de amido foi utilizada uma porcentagem significativa de água e, provavelmente, ocorre a presença de água residual ligada na estrutura da matriz polimérica, após o processo de obtenção do filme, que foi realizado em estufa a $35^{\circ} \mathrm{C}$, por 8 horas. 


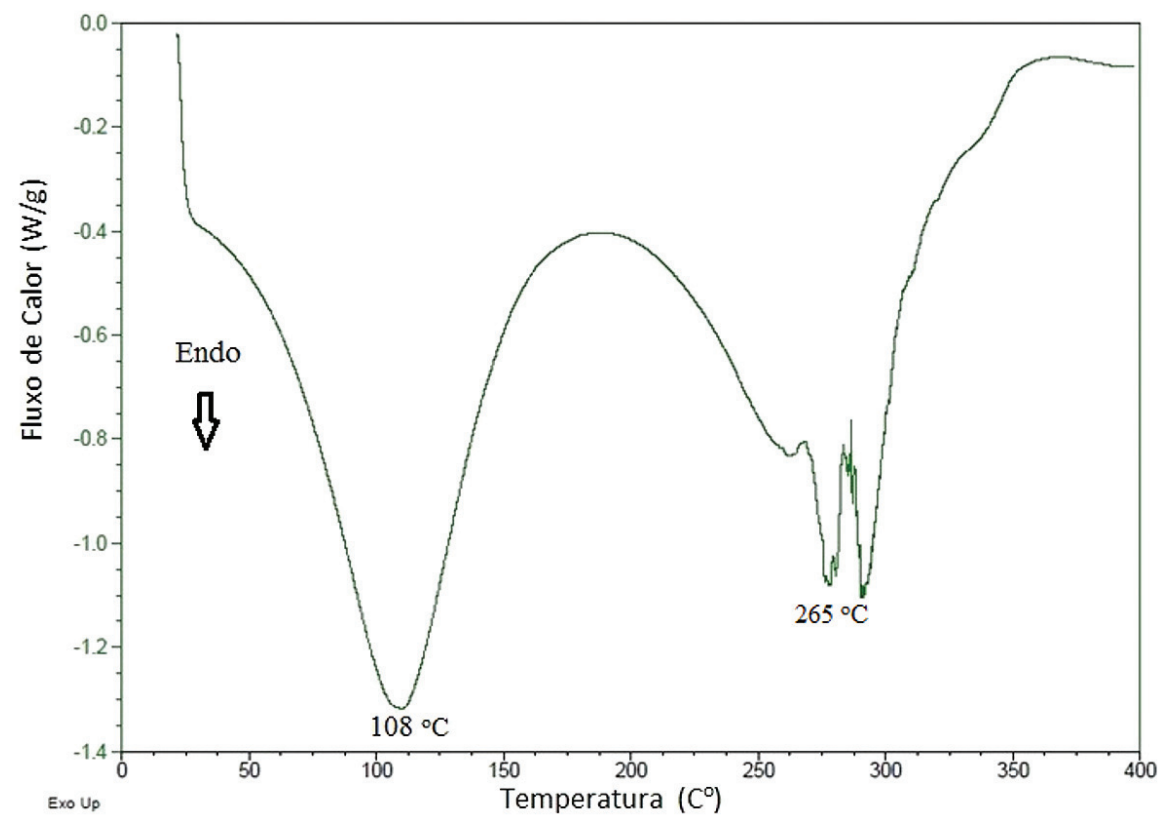

Figura 4. Curva de DSC da amostra de filme $0 \%$ de lignossulfonato.

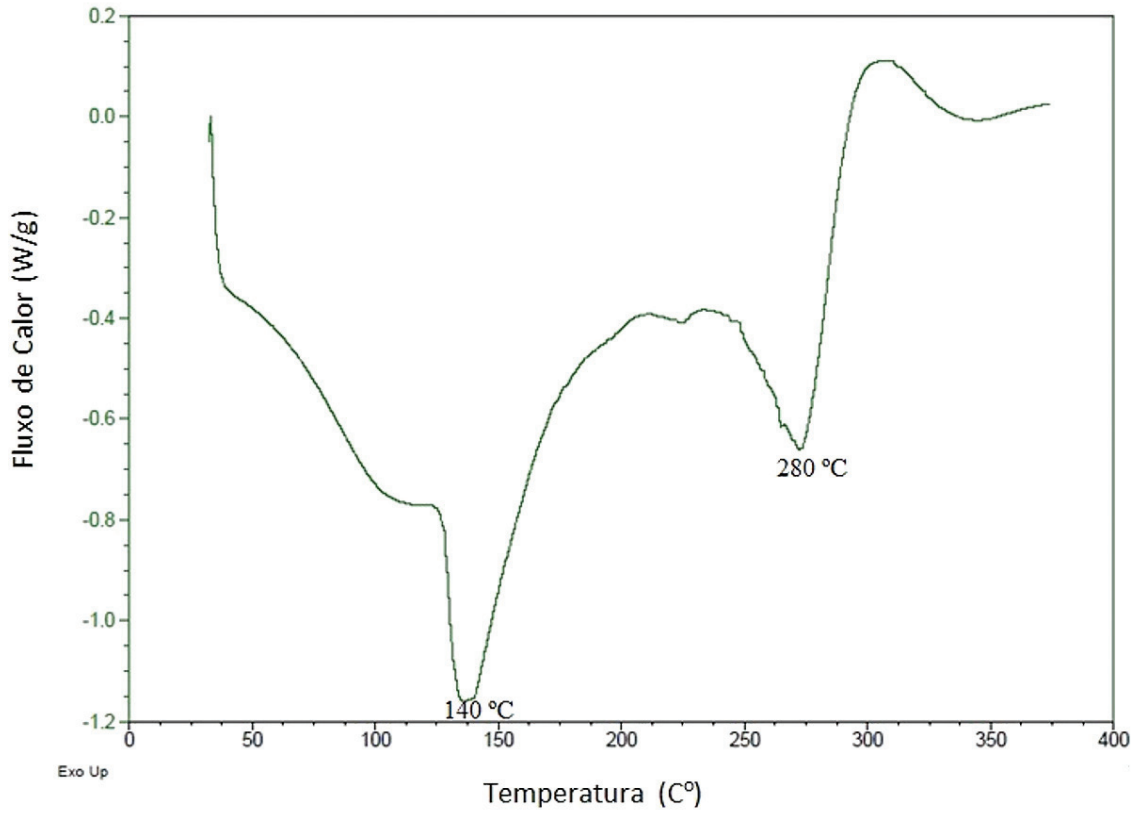

Figura 5. Curva de DSC da amostra de filme com $4 \%$ de lignossulfonato Vixil S.

$\mathrm{Na}$ literatura ${ }^{[49]}$ pode ser encontrado um trabalho que relata um pico endotérmico em torno de $150{ }^{\circ} \mathrm{C}$ para filme de amido contendo $30 \%$ em massa de glicerol. No entanto, no caso do trabalho ${ }^{[49]} \mathrm{o}$ amido de milho utilizado continha aproximadamente $24 \%$ de amilose. Além disto, algumas amostras analisadas no trabalho ${ }^{[49]}$ continham também quitina e quitosana, que foram misturadas anteriormente, a $140^{\circ} \mathrm{C}$ por $15 \mathrm{~min}$., para obter formulações para moldagem de diversos filmes, que na análise de DSC apresentaram pequenas alterações no valor do pico endotérmico observado.
No caso dos experimentos em que foram utilizados os lignossulfonatos Vixil S foi notada pela análise de DSC que ocorreu um deslocamento no pico relacionado à fusão da amostra para o intervalo de 110 a $140{ }^{\circ} \mathrm{C}$ (pico máximo, Figura 5). Também pode ser observada alteração no perfil da curva devido à incorporação do lignossulfonato (Figura 5).

Em relação à amostra de filme polimérico $0 \%$ de lignossulfonato (Figura 4) analisada e amostras de filmes contendo lignossulfonato Vixil I (figuras não mostradas), bem como para amostras de filmes contendo lignossulfonato Vixil Tan (figuras não mostradas) foi 
notada que a decomposição térmica do filme ocorre em aproximadamente $265^{\circ} \mathrm{C}$.

As decomposições térmicas das amostras de filmes contendo lignossulfonato Vixil S a 1\%, 2\% e 4\% (Figura 5) foram observadas a partir de aproximadamente $240{ }^{\circ} \mathrm{C}$, com pico na temperatura de $280^{\circ} \mathrm{C}$, fato indicativo de uma maior estabilidade térmica dos filmes contendo lignossulfonato Vixil S.

\section{Teste de biodegradabilidade}

Em relação ao teste de biodegradabilidade das amostras foram feitas as identificações de três gases, $\mathrm{CH}_{4}, \mathrm{CO}_{2} \mathrm{e}$ $\mathrm{N}_{2} \mathrm{O}$, utilizando a técnica de cromatografia. Considerando a emissão de metano $\left(\mathrm{CH}_{4}\right)$ das amostras (Figura 6) foi verificado que houve praticamente a mesma liberação em todos os frascos, ou seja, os frascos que continham somente as amostras de solo, os que continham o polímero com $0 \%$ de lignossulfonato, e os que continham polímero mais lignossulfonato Vixil S com concentração de 4\%. Além disso, na quarta semana foram computados valores menores que zero relacionados ao metano, revelando que houve consumo de $\mathrm{CH}_{4}$ pelo sistema, já que alguns microorganismos do solo têm essa característica ${ }^{[38,40,43]}$.

Em relação à emissão de $\mathrm{CO}_{2}$ (Figura 7) pode ser notado que as amostras de filmes poliméricos contendo lignossulfonato (Vixil S) emitiram maior quantidade de gás carbônico em sua degradação, em relação às demais amostras $(p<0,05)$. Este resultado demonstra que o filme contendo o lignossulfonato (o qual apresenta maior quantidade de átomos de carbono na estrutura comparando com o filme contendo somente o amido), apresentou maior degradabilidade pois liberou mais $\mathrm{CO}_{2}$ em relação às amostras de solo e de filme contendo somente o amido. Além disto, o material pode ter estimulado a atividade microbiana do solo ocasionando a degradação de matéria orgânica mais estável do solo devido ao efeito priming ${ }^{[50]}$. O mesmo efeito pode ter sido o responsável pela ocorrência de emissão de $\mathrm{N}_{2} \mathrm{O}$ nas amostras contendo lignossulfonato (Figura 8). Adicionalmente, a possível presença de $\mathrm{N}$ na estrutura do material incubado pode ter sido liberado durante o processo de degradação. Ainda, não pode ser descartada a possibilidade da presença do nitrogênio estar relacionada a algum contaminante químico residual do processo industrial de modificação da lignina. De qualquer forma as emissões de $\mathrm{N}_{2} \mathrm{O}$ ocasionadas com a presença dos materiais adicionados ao solo são pouco significativas quando comparadas com materiais orgânicos e fertilizantes nitrogenados frequentemente adicionados em solos agrícolas ${ }^{[42]}$.

Ainda considerando a Figura 8, vale ressaltar que embora tenham ocorrido emissões positivas tanto de $\mathrm{CO}_{2}$ como $\mathrm{N}_{2} \mathrm{O}$ do material incubado, os valores observados são significativamente menores que valores de emissões naturais encontradas em florestas tropicais tais como a Amazônia e Mata Atlântica ${ }^{[51]}$.

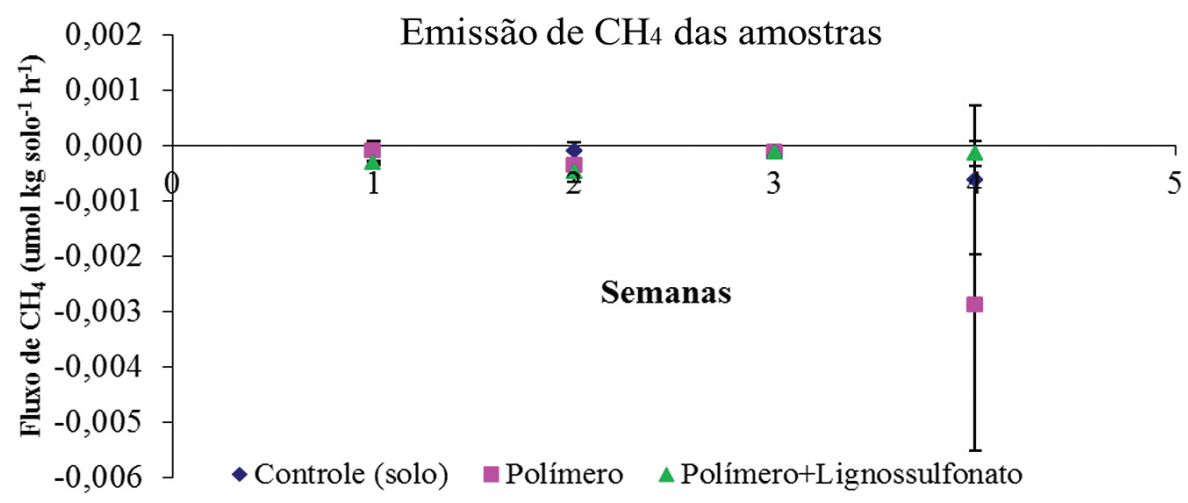

Figura 6. Emissão de $\mathrm{CH}_{4}$ das amostras no teste de biodegradabilidade.

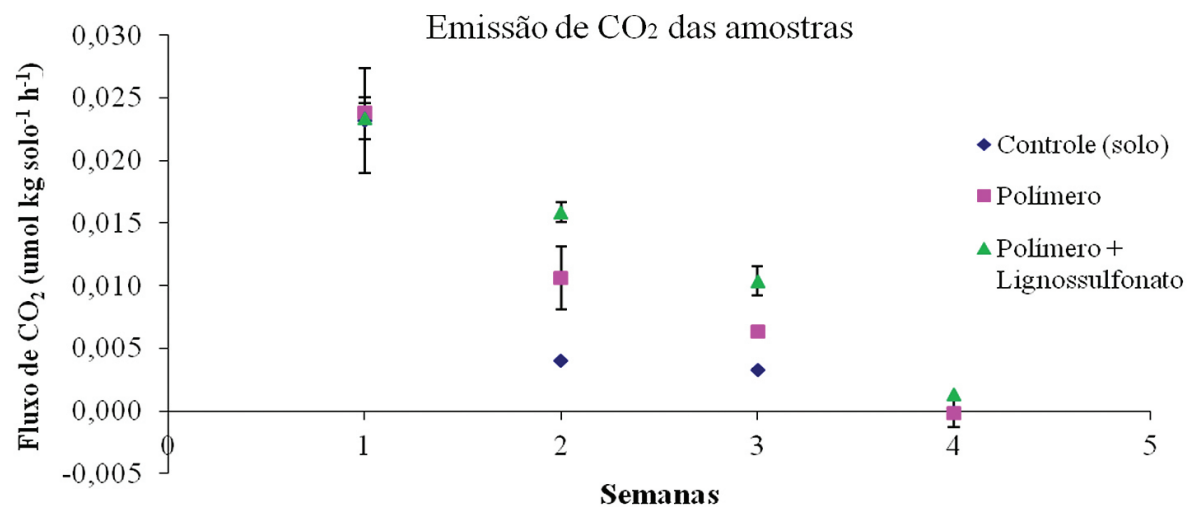

Figura 7. Emissão de $\mathrm{CO}_{2}$ das amostras no teste de biodegradabilidade. 


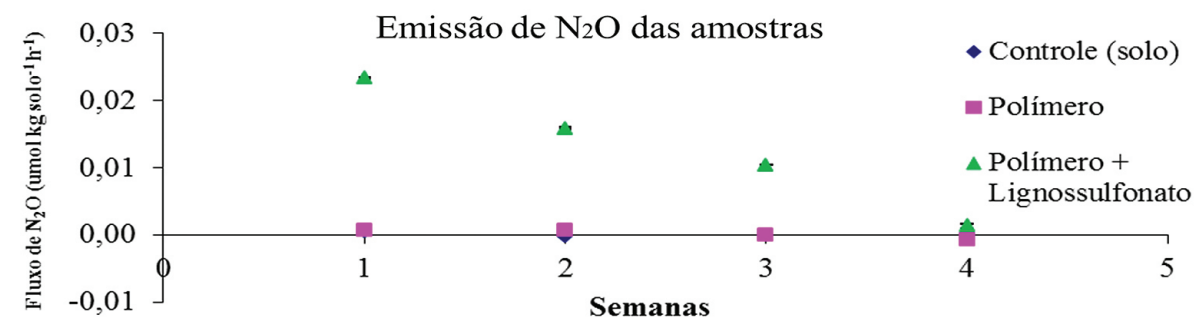

Figura 8. Emissão de $\mathrm{N}_{2} \mathrm{O}$ das amostras no teste de biodegradabilidade.

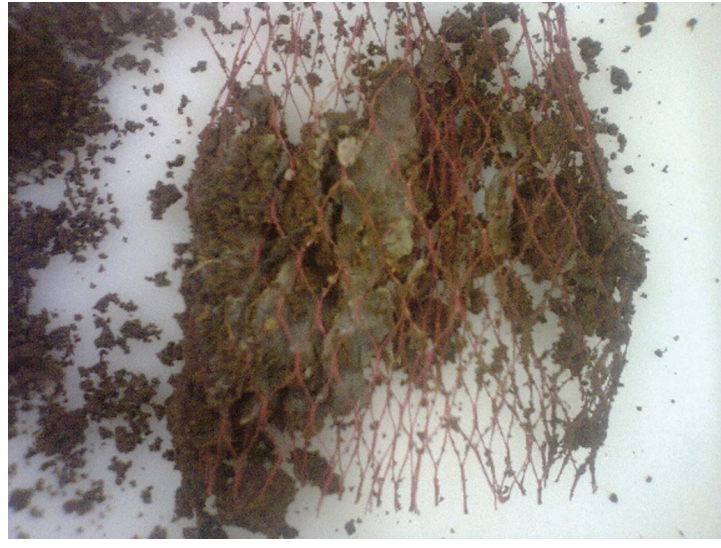

Figura 9. Amostra de filme de amido com $4 \%$ de lignossulfonato Vixil S, retirado após a $5^{\mathrm{a}}$ semana de condicionamento em solo.

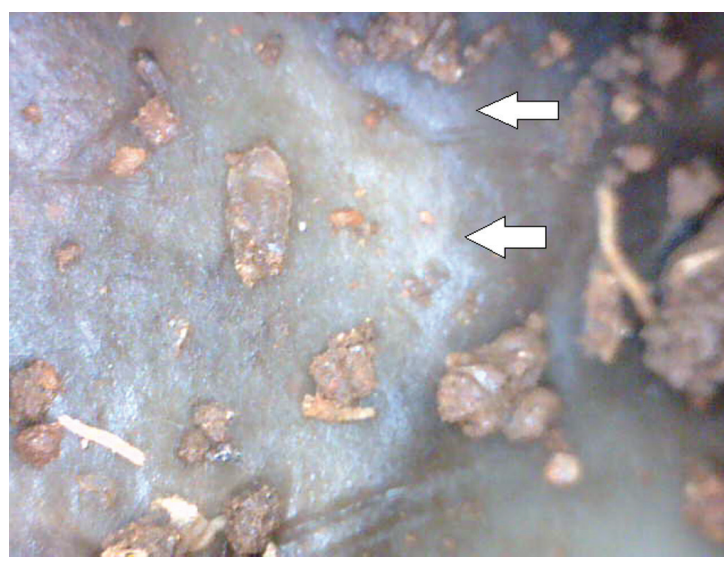

Figura 10. Amostra de filme de amido com $4 \%$ de lignossulfonato Vixil S, retirado após a $8^{\mathrm{a}}$ semana de condicionamento em solo. Ampliação 50X.

Após a $5^{\text {a }}$ semana de coleta de dados, as amostras foram retiradas do solo para verificar seus aspectos físicos. Foi observado que os filmes poliméricos não estavam mais interiços, porém com sobras de alguns resíduos como, por exemplo, mostrados na Figura 9. Este aspecto foi similar para todas as amostras de filmes poliméricos retirados do solo. Então, posteriormente, as amostras de filmes foram novamente condicionadas no sistema de frascos de vidro contendo o solo.

Após cerca de dois meses da data inicial de condicionamento em solo, as amostras foram retiradas novamente dos frascos de vidro e foi possível avaliar através de observações visuais e fotografias que os filmes poliméricos contendo lignossulfonato (Vixil S) aparentavam terem se degradado significativamente, porém alguns resíduos dos filmes poliméricos (indicados pelas setas) ainda foram observados em microscópio digital portátil (Dino-Lite plus, modelo AM7013MT), como mostrado na Figura 10

Após quatro meses da data inicial em que as amostras foram enterradas no solo contido nos frascos de vidro, elas foram retiradas para verificar seus aspectos físicos $\mathrm{e}$ não mais foi observada, em microscópio digital portátil a presença dos filmes poliméricos, restando somente solo. Não foi possível realizar análise por microscopia eletrônica de varredura dos resíduos das amostras retiradas do solo devido às diversas partículas de solo presentes, as quais poderiam ser succionadas pelo vácuo danificando o equipamento.

\section{Conclusões}

O trabalho desenvolvido atingiu o objetivo de incorporar alguns tipos de lignossulfonatos em filmes poliméricos de amido. Desta maneira foi evidenciada a possibilidade de incorporar um resíduo da indústria de papel e celulose a este tipo de filme polimérico.

Em relação aos ensaios mecânicos de tração realizados no DMTA, várias amostras de filmes poliméricos contendo lignossulfonatos apresentaram menor resistência à tração quando comparados aos filmes poliméricos de amido. No entanto, o filme polimérico contendo $1 \%$ de lignossulfonato do tipo Vixil $\mathrm{S}$ apresentou valores de resistência à tração próximos aos do filme polimérico contendo amido, sem lignossulfonato.

Considerando as análises realizadas em equipamento de DSC foram notadas semelhanças nas propriedades térmicas dos filmes de amido e dos filmes contendo lignossulfonatos. A incorporação de lignossulfonato nos filmes ocasionou deslocamento no pico endotérmico relacionado à fusão da fase cristalina do amido presente nos filmes poliméricos. Para os filmes contendo lignossulfonato Vixil $\mathrm{S}$ foi observado um deslocamento da temperatura de início de decomposição térmica, o que pode ser indicativo de melhoria de estabilidade térmica.

Este trabalho revelou que o teste de biodegradabilidade realizado com auxílio do método por cromatografia obteve bons resultados. Foi possível analisar gases emitidos durante a biodegradação dos filmes e observar que as maiores emissões de gás carbônico e de óxido nitroso 
foram liberadas pela biodegradação das amostras dos filmes poliméricos contendo 4\% de lignossulfonato Vixil S.

Dessa forma, dependendo da finalidade, tais filmes poliméricos contendo lignossulfonato podem ser utilizados como uma alternativa para algumas embalagens, como tubetes ou filmes para áreas de plantações, mantendo a vantagem de ser um material biodegradável. No entanto, em relação às emissões de $\mathrm{N}_{2} \mathrm{O}$ ainda é preciso avaliar a magnitude dessas emissões, por este gás geralmente persistir por mais tempo na atmosfera.

\section{Agradecimentos}

À FAPESP(Projeto número 06/60885-2) e ao CNPq. Ao Prof. Dr. Vagner R. Botaro pelo empréstimo do equipamento DMA. À empresa Lignotech Brasil (Borregaard Ind. Ltd.) pelo fornecimento dos lignossulfonatos.

\section{Referências Bibliográficas}

1. Huang, S. J. - J. Mat Science - Pure Appl. Chem., A32, p.493 (1995).

2. Parra, D. F.; Tadini, C.; Ponce, P. \& Lugao, A. Carbohydrate., 58, p.475 (2004). http://dx.doi.org/10.1016/j. carbpol.2004.08.021.

3. Chiellini, E. \& Solaro, R. - "Environmentally Degradable Polymers and Plastics. An Overwiew", in: Anais do International Workshop on Environmentally Degradable and Recyclable Polymers in Latin America, p.15, Campinas - SP, nov (1998).

4. Mohanty, A. K.; Misra, M. \& Drzal, L. T. - J. Polym. Environ., 10, p.19(2002). http://dx.doi.org/10.1023/A:1021013921916.

5. Da Roz, A. - Polímeros., 13, p.E4 (2003). http://dx.doi. org/10.1590/S0104-14282003000400003.

6. Abatti, L. \& Domingues Junior, N. S. - Polímeros., 21, p.151 (2011). http://dx.doi.org/10.1590/S010414282011005000026.

7. Scott, G. - "Polymer and the Environment", The Royal Society of Chemistry, Letchworth (1995).

8. Corradini, E.; Lotti, C.; Medeiros, E. S.; Carvalho, A. J. F.; Curvelo, A. A. S. \& Mattoso, L. H. C. - Polímeros., 15, p.268 (2005). http://dx.doi.org/10.1590/S010414282005000400011.

9. French, D. - "Starch chemistry and technology", Academic Science, New York (1984).

10. Thiré, R. M. S. M.; Simão, R. A.; Araújo, P. J. G.; Achete, C. A. \& Andrade, C. T. - Polímeros., 14, p.57 (2004). http:// dx.doi.org/10.1590/S0104-14282004000100015.

11. Schwach, E.; Six, J.-L. \& Avérous, L. - J. Polym. Environ., 16, p.286 (2008). http://dx.doi.org/10.1007/s10924-008-0107-6.

12. Ciobanu, C.; Ungureanu, M.; Ignat, L.; Ungureanu, D. \& Popa, V. I. - Ind. Crops Prod., 20, p.231 (2004). http://dx.doi. org/10.1016/j.indcrop.2004.04.024.

13. Rosa, D. S.; Franco, B. L. M. \& Calil, M. R. - Polímeros., 11, p.82 (2001). http://dx.doi.org/10.1590/S010414282001000200010 .

14. Rosa, D. S. - Polímeros., 12, p.311 (2002).

15. Brito, G. F. - REMAP, 6, p.127 (2011).

16. Ortega-Toro, R.; Jiménez, A.; Talens, P. \& Chiralt, A. - Food Hydrocoll., 38, p.66 (2014). http://dx.doi.org/10.1016/j. foodhyd.2013.11.011.

17. Lopez, O.; Garcia, M.A.; Villar, M.A.; Gentili, A.; Rodriguez, M. S.; Albertengo, L. - LWT - Food Science and Technology, 57, p.106 (2014).
18. Dieulot, J.-Y. \& Skurtys, O. - J. Food Eng., 119, p.188 (2013). http://dx.doi.org/10.1016/j.jfoodeng.2013.05.028.

19. Ghasemlou, M.; Aliheidari, N.; Fahmi, R.; Shojaee-Aliabadi, S.; Keshavarz, B.; Cran, M. J. \& Khaksar, R. - Carbohydr. Polym., 98, p.1117 (2013). http://dx.doi.org/10.1016/j. carbpol.2013.07.026. PMid:23987453

20. Forest Products Laboratory - "Wood Handbook: Wood as an Engineering Material. General Technical Report FPLGTR-190", U.S. Department of Agriculture, Forest Service, Forest Products Laboratory, Madison (2010).

21. Carvalho, G. \& Frollini, E. - Polímeros, 9, p.66 (1999).

22. Tita, S. P. S.; Paiva, J. M. F. \& Frollini, E. - Polímeros., 12, p.228 (2002). http://dx.doi.org/10.1590/S010414282002000400005 .

23. Faulstich de Paiva, J. M. \& Frollini, E. - Macromol. Mater. Eng., 291, p.405 (2006). http://dx.doi.org/10.1002/ mame.200500334.

24. Paiva, J. M. F.; Trindade, W. G. \& Frollini, E. - Polímeros., 9, p.170 (1999). http://dx.doi.org/10.1590/S010414281999000400028.

25. Hon, D. N.-S. - "Weathering and Photochemistry of Wood", in: Wood and Cellulosic Chemistry, 2. ed., David N.-S. Hon and Nobuo Shiraishi (eds.), Marcel Dekker Inc., New York (2001).

26. Fengel, D. \& Wegener, G. - "Wood Chemistry, Ultrastructure and Reactions", Walter de Grutyer, Berlin (1989).

27. Santos, M. F. R. F. - "Elaboração da Technology Roadmap para Biorrefinaria de Produtos da Lignina no Brasil", Tese de Doutorado, Universidade Federal do Rio de Janeiro, Brasil (2011).

28. Areskogh, D. - "Structural Modifications of Lignosulphonates", Doctoral Thesis, Royal Institute of Technology, Sweden (2011).

29. Doherty, W. O. S.; Mousavioun, P. \& Fellows, C. M. - Ind. Crops Prod., 33, p.259 (2011). http://dx.doi.org/10.1016/j. indcrop.2010.10.022.

30. Reknes, K. - "The chemistry of lignosulphonate and the effect on performance of lignosulphonate base plasticizers and superplasticizers", in: 29th Conference on Our World in Concrete \& Structures, p.433, Singapore, ago (2004). Article Online Id: 100029055

31. Melbar Produtos de Lignina - "Especificação Técnica de Lignossulfonatos", Lignotech Brasil Produtos de Lignina. Melbar, Melhoramentos, São Paulo (2002).

32. Mishra, S. B.; Mishra, A. K.; Kaushik, N. K. \& Khan, M. A. - J. Mater. Process. Technol., 183, p.273 (2007). http://dx.doi. org/10.1016/j.jmatprotec.2006.10.016.

33. Luckachan, G. E. \& Pillai, C. K. S. - Journal of Polymer and Environ., 19, p.637 (2011). http://dx.doi.org/10.1007/s10924011-0317-1.

34. Coelho, N. S.; Almeida, Y. M. B. \& Vinhas, G. M. Polímeros., 18, p.270 (2008). http://dx.doi.org/10.1590/ S0104-14282008000300014.

35. Souza, P. M. S. \& Morales, A. R. - Polímeros., 24, p.110 (2014).

36. Gattin, R.; Copinet, A.; Bertrand, C. \& Couturier, Y. - Int. Biodeterior. Biodegradation., 50, p.25 (2002). http://dx.doi. org/10.1016/S0964-8305(02)00039-2.

37. Pedroso, M. P.; Godoy, L. A. F.; Fidélis, C. A. V.; Ferreira, E. C.; Poppi, R. J. \& Augusto, F. - Quim. Nova., 32, p.422 (2009). http://dx.doi.org/10.1590/S0100-40422009000200029.

38. Carmo, J. B.; Andrade, C. A.; Cerri, C. C. \& Piccolo, M. C. - Rev. Bras. Cienc. Solo., 29, p.735 (2005). http://dx.doi. org/10.1590/S0100-06832005000500009. 
39. Lopes, P. A. - "Estatística Aplicada à Análise de Resultados de Ensaios de Proficiência na Avaliação de Laboratórios", Anvisa/Instituto Adolpho Lutz, Rio de Janeiro (2003).

40. Carmo, J. B.; Piccolo, M. C.; Andrade, C. A.; Cerri, C. E. P.; Feigl, B. J.; Neto, E. S. \& Cerri, C. C. - Soil Tillage Res., 96, p.250 (2007). http://dx.doi.org/10.1016/j.still.2007.06.002.

41. Embrapa - "Sistema Brasileiro de Classificação de Solos", 2. ed., Embrapa, Rio de Janeiro (2006).

42. de Urzedo, D. I.; Franco, M. P.; Pitombo, L. M. \& do Carmo, J. B. - For. Ecol. Manage., 310, p.37 (2013). http://dx.doi. org/10.1016/j.foreco.2013.08.018.

43. Keller, M. \& Reiners, A. - Global Biogeochem. Cycles., 8, p.399 (1994). http://dx.doi.org/10.1029/94GB01660.

44. Varner, R. K.; Keller, M.; Robertson, J. R.; Dias, J. D.; Silva, H.; Crill, P. M.; Mcgroddy, M. \& Silver, W. L. Geophys. Res. Lett., 30, p.1144 (2003). http://dx.doi. org/10.1029/2002GL016164.

45. Jantalia, C. P.; dos Santos, H. P.; Urquiaga, S.; Boddey, R. M. \& Alves, B. J. R. - Nutr. Cycl. Agroecosyst., 82, p.161 (2008). http://dx.doi.org/10.1007/s10705-008-9178-y.

46. Carmo, J. B.; Filoso, S.; Zotelli, L. C.; Sousa Neto, E. R.; Pitombo, L. M.; Duarte-Neto, P. J.; Vargas, V. P.; Andrade,
C. A.; Gava, G. J. C.; Rosseto, R.; Cantarella, H.; Neto, A. E. \& Martinelli, L. A. - GCB Bioenergy., 5, p.267 (2013).

47. Richardson, G.; Sun, Y.; Langton, M. \& Hermansson, A.M. - Carbohydr. Polym., 57, p.369 (2004). http://dx.doi. org/10.1016/j.carbpol.2004.04.023.

48. Privas, E.; Leroux, F. \& Navard, P. - Carbohydr. Polym., 96, p.91 (2013). http://dx.doi.org/10.1016/j.carbpol.2013.03.042. PMid:23688458

49. Lopez, O.; Garcia, M.A.; Villar, M. A.; Gentili, A.; Rodriguez, M. S. \& Albertengo, L. - LWT - Food Science and Techn., 57, p.106 (2014).

50. Burns, R. G.; DeForest, J. L.; Marxsen, J.; Sinsabaugh, R. L.; Stromberger, M. E.; Wallenstein, M. D.; Weintraub, M. N. \& Zoppini, A. - Soil Biol. Biochem., 58, p.216 (2013). http:// dx.doi.org/10.1016/j.soilbio.2012.11.009.

51. Sousa Neto, E.; Carmo, J. B.; Keller, M.; Martins, S. C.; Alves, L. F.; Vieira, S. A.; Piccolo, M. C.; Camargo, P.; Couto, H. T. Z.; Joly, C. A. \& Martinelli, L. A. - Biogeosciences., 8, p.733 (2011). http://dx.doi.org/10.5194/bg-8-733-2011.

Enviado: Fev. 28, 2014 Reenviado: Ago. 24, 2014 Aceito: Set. 01, 2014 